\title{
THE EVOLUTION OF FACILITATED INDUSTRIAL SYMBIOSIS
}

\author{
Raymond L Paquin \\ rpaquin@jmsb.concordia.ca \\ Department of Management \\ John Molson School of Business \\ Concordia University \\ Canada \\ Jennifer Howard-Grenville \\ jhg@uoregon.edu \\ Department of Management \\ Lundquist College of Business \\ University of Oregon \\ USA
}

Forthcoming, 2012 Journal of Industrial Ecology

\section{KEYWORDS}

Industrial symbiosis (IS), Facilitated industrial symbiosis, Evolution, Coordination, National Industrial Symbiosis Programme (NISP)

\section{SUMMARY}

While much work has been done on the conditions surrounding the emergence and establishment of industrial symbiosis, new attention is being paid to understanding the evolution of industrial symbiosis over time. We demonstrate empirically how a new facilitated industrial symbiosis initiative developed and evolved over an eight-year period. We explore its network evolution by considering how the facilitator's actions enabled and precluded two fundamental network processes - serendipitous and goal-directed processes. We discuss implications for a more generalized theory of industrial symbiosis development by exploring why and how different evolutionary trajectories may unfold. 
$<$ Heading 1> INTRODUCTION

How does industrial symbiosis evolve? Researchers have documented a variety of ways in which industrial symbiosis emerges, including self-organization (Chertow 2007; Ehrenfeld and Gertler 1997), facilitation by organizations or individuals (Paquin and HowardGrenville 2009; Hewes and Lyons 2008; Van Beers et al. 2007; Shi et al. 2010), and top-down planning (Gibbs and Deutz 2007; Chertow 2007). Less clear is how industrial symbiosis arrangements - which can be understood as inter-firm networks (Ashton 2008; Doménech and Davies 2010; Howard-Grenville and Paquin 2008) - develop and change over time. Do self-organizing, facilitated, and planned industrial symbiosis display similar patterns of evolution or develop along distinct trajectories? Several recent models seek to explain industrial symbiosis evolution (Baas and Boons 2004; Chertow and Ehrenfeld 2010; Doménech and Davies 2010). While these provide necessary insight into stages of industrial symbiosis development, additional empirical study is needed, especially to understand the evolution of facilitated industrial symbiosis.

Industrial symbiosis (IS) and organizational theory literatures discern two fundamentally different processes underpinning interfirm network evolution. IS literature draws a distinction between IS arrangements arising through self-organization and those formed via third party planning (Chertow 2007; Ehrenfeld and Gertler 1997; Gibbs and Deutz 2007; Hewes and Lyons 2008). Organizational theory draws a distinction between 'serendipitous' and 'goal-directed' network processes (Kilduff and Tsai 2003). Serendipitous processes occur through the "happenstance of people meeting and liking one another," while goal-directed processes occur when "parties interact to achieve, plan, coordinate, or decide on their individual and collective activities" (Salancik 1995: 346). Conceptually these processes and the resulting networks differ; in practice, many networks reflect the workings 
of both processes (Kilduff and Tsai 2003). Thus, we investigate how serendipitous ('selforganizing') and goal-directed ('planned') processes influence the evolution of a facilitated IS network.

Facilitated IS represents a middle ground between self-organized and planned IS (Paquin and Howard-Grenville 2009), offering a good empirical setting to explore the interaction of these fundamental network-development processes. Using qualitative and quantitative data, we explore longitudinally the evolution of the National Industrial Symbiosis Programme's (NISP) facilitated IS network over an eight year period. While goaldirected processes are expected to dominate in a setting where a facilitator actively assembles a network (Dyer and Nobeoka 2000; Kilduff and Tsai 2003), we find a somewhat surprising role for serendipity, especially early in the network's growth. Furthermore, we find that goal-directed processes grow more prevalent as the facilitator gains expertise and experience.

Using our empirical findings, we discuss general implications for the interaction between serendipitous and goal-directed processes of IS evolution and the combined influence these processes have on IS resilience. We argue that IS development over time might be better captured through an understanding of how these underlying processes coevolve, rather than through classifying IS according to type (i.e., self-organizing, planned, or facilitated).

\section{$<$ Heading 1> PATTERNS OF INDUSTRIAL SYMBIOSIS DEVELOPMENT}

IS networks arise from distinct initial conditions. Emergent or self-organizing IS develops in a decentralized fashion, and, once 'uncovered', may become managed by a coordinating organization (Chertow 2007). Anchor tenants provide resources and/or expertise to 
generate IS among proximate firms (Chertow et al. 2008; Korhonen 2001). Alternatively, coordinators bring firms or individuals together to develop IS networks (Baas and Boons 2004; Hewes and Lyons 2008; Mirata 2004; Shi et al. 2010; Van Beers et al. 2007). Finally, coordinating organizations recruit companies to co-locate and share services or exchange by-products through eco-industrial parks (Gibbs and Deutz 2007; Chertow and Ehrenfeld 2010).

$<$ Heading 2> Stage Models of Industrial Symbiosis Network Development

Scholars used these different observed starting points to theorize IS development. We found three models describing IS stages. Baas and Boons (2004), studying IS in Rotterdam harbor, conceptualized three stages - regional efficiency, regional learning, and sustainable industrial district - each involving more in-depth engagement among firms. In particular, they suggested firms may move from individual resource efficiency-based exchanges to deeper strategic collaborations around sustainable goals and actions.

Chertow and Ehrenfeld (2010) conceptualized self-organizing IS development. Similar to Baas \& Boons' first two stages, they proposed emergence and uncovering stages where firms engage in individual resource efficiency exchanges until their actions are 'uncovered' - made public in some fashion. Uncovering creates the impetus for firms to broaden their environmental goals and pursue additional IS opportunities. Once uncovered, embeddedness and institutionalization occur as firms continue developing norms of trust and reciprocity and a 'coordinating institution' arises to further support firms' actions.

Drawing on three IS cases, Doménech and Davies (2010) suggest slightly different IS stages - emergence, probation, and development and expansion - each involving progressively more cooperation among firms. Emergence resembles the above models as 
firms likely initially engage in straightforward resource exchanges. Doménech \& Davies found early exchanges may occur through decentralized (e.g., self-organizing) or coordinated action. In probation and development and expansion stages firms develop greater awareness of and expertise in IS, and develop new and strengthen existing IS relationships.

In each model, IS development matures as trust and shared norms of interaction governing IS exchanges develops (Ashton 2008; Baas and Boons 2004). Additionally, these models suggest opportunities for more complex exchanges and collaborations increase as such norms evolve. The IS literature captures these aspects of IS development as 'embeddedness' (Boons and Howard-Grenville 2009).

$<$ Heading 2> Embeddedness and Industrial Symbiosis Network Development

Embeddedness broadly describes the impacts of actors' social interaction patterns and practices on their economic and organizational actions (Boons and Howard-Grenville 2009; Burt 1992), and is increasingly discussed in terms of structural, cultural, cognitive and political dimensions of embeddedness (Dacin et al. 1999). Structural embeddedness suggests the strength, quality, and type of information flow among individuals or firms influences outcomes (Uzzi 1996; Granovetter 1985). Cultural and cognitive embeddedness capture the norms governing individual and group actions and interactions (Boons and Howard-Grenville 2009; Powell et al. 2005); suggesting overall, that embeddedness enables, rather than constrains, action by reducing social 'transaction costs,' through information flow and norms of reciprocity (Powell et al. 2005).

Cultural embeddedness seems particularly important in IS evolution; trust and norms of reciprocity enable robust structural ties around resource exchanges to develop (Ashton 
2008; Ehrenfeld and Gertler 1997; Hewes and Lyons 2008). However, organizational theory on network development and evolution suggests networks emerge not only from cultural embeddedness, but can come about in other ways (Dyer and Nobeoka 2000; Gulati and Gargiulo 1999; Uzzi 1996). Kilduff and Tsai (2003) discern 'serendipitous' network processes from 'goal-directed' ones - the former foregrounding cultural embeddedness, the latter structural embeddedness.

\section{$<$ Heading 2> Serendipitous and Goal-Directed Network Processes}

Serendipitous network processes, paralleling those of self-organizing IS, develop in an undirected fashion, without an overarching collective goal or coordinating body (Kilduff and Tsai 2003). They tend to occur when the potential gains of joining the network are evident and firms can readily access each other to create value. When serendipitous processes drive network evolution, firms are motivated to join and develop particular network ties because doing so can serve individual, rather than collective, goals. These networks tend to grow slowly (Baum et al. 2003; Powell et al. 1996), yet are typically resilient as they build upon pre-existing ties and relationships (Gulati and Gargiulo 1999; Uzzi 1996). Serendipitous processes lead to relatively long-lasting, multi-connected networks where early entrants and central firms can influence interaction norms and hold privileged structural positions over time (Powell et al. 2005).

Conversely, goal-directed network processes involve coordinators intentionally bringing others together to achieve collective or network-level goals (Dhanaraj and Parkhe 2006; Human and Provan 2000; Powell et al. 2009). Actors developing such networks influence the network's common goals, shape collective norms, and play a role in deciding whether and how particular other actors join the network (Doz et al. 2000; Powell et al. 
2005; Dietz et al. 2003). Supply chain, innovation network, and business support research provide empirical examples of networks resulting from goal-directed processes (Dyer and Nobeoka 2000; Doz et al. 2000; Human and Provan 2000). These networks tend to grow rapidly initially, displaying a distinct "hub [coordinator] and spoke [firms]" structure, with firms connected to each other through the coordinator (Doz et al. 2000; Dyer and Nobeoka 2000). Accordingly, the coordinator tends to hold disproportionate influence over the network's structure and norms of engagement.

Serendipitous and goal-directed network processes suggest embeddedness may develop differently over time in self-organizing versus facilitated IS networks. Specifically, when serendipitous processes dominate, cultural embeddedness may serve as a foundation for generating new exchanges, thus preceding structural embeddedness. Conversely, when goal-directed processes dominate, structural embeddedness is more important initially, as a coordinator brokers connections to firms around new exchanges. Cultural embeddedness (shared norms) may or may not develop in a network dominated by goal-directed processes. In practice, serendipitous and goal-directed network processes are usually not fully exclusive of each other. Rather, developing networks typically display some combination of the two (Paquin and Howard-Grenville 2009; Doz et al. 2000; Powell et al. 2009). The particular way these processes interact will influence network resilience and robustness (Capaldo 2007). Our exploration of the longitudinal evolution of a facilitated IS network illuminates how these two fundamental processes and associated dimensions of embeddedness unfold and shape how the network evolves. Understanding how goal-directed and serendipitous processes interact holds promise for informing our understanding of IS evolution in facilitated, planned, and self-organizing systems. Furthermore, while embeddedness is associated with network stability and resilience, some researchers in industrial ecology and 
economic sociology have voiced concerns that 'over' embeddedness may inhibit renewal and adaptation to change (Uzzi 1996; Burt 1992; Doménech and Davies 2010). By exploring how a facilitated IS network develops we can also build theory on how particular processes shape the overall network's resilience.

\section{$<$ Heading 1> METHODS}

We took a grounded theory approach to exploring these questions to understand the underlying processes (Langley 1999) of IS evolution. We focus on the facilitator's actions and the influence these actions have on the processes of network development. <Heading 2> Empirical Setting: National Industrial Symbiosis Programme (NISP)

Our data are drawn from the United Kingdom's National Industrial Symbiosis Programme (NISP), the world's first national-level industrial symbiosis program. Though national in scope, NISP grew out of - and operates as - a collection of semi-autonomous regionally-focused IS programs throughout the UK (Mirata 2004; Doménech and Davies 2010). NISP's April 2005 national launch grew from earlier success in IS programs in individual regions. As NISP's longest continuously running regional IS program (since 2002), the West Midlands is arguably the most mature and developed region. For this reason, of our four regions studied (East Midlands, West Midlands, North East, North West), we conduct our most in-depth study there.

$<$ Heading 2> Data

From December 2005 to May 2009, we took a grounded theory approach to inductively explore (Glaser and Strauss 1967) NISP's actions in developing IS regionally, and probed how these actions influenced the underlying processes driving the evolution of the 
IS network. We focused our qualitative analysis on NISP's perspectives and those of firms involved with NISP. Our quantitative analysis looked at the structure and types of exchanges in the West Midlands. Our study used three sources of data - interviews, observations, and archival documents.

$<$ Heading 3 > Interview Data

We conducted in-depth interviews with 20 NISP staff from headquarters and four regions (West Midlands, East Midlands, Northeast, and Northwest), 24 firms from two regions (West Midlands and East Midlands), and had informal conversations and unstructured interviews with an additional 35 NISP staff - totaling over half of NISP's staff during the study period. We theoretical sampled (Patton 2001) firms to interview to generate a diverse representation of size, industry, and participation level with NISP ranging from voiced interest to active involvement on multiple IS projects. When possible, we digitally recorded interviews and conversations and took real-time handwritten notes. We collected firm interviews in 2006, but conducted NISP staff interviews throughout the study period. For this paper, we use NISP staff interviews conducted over time to qualitatively capture changing facilitation actions and their impact on the IS network.

\section{$<$ Heading 3> Observational and Archival Data}

We spent 37 days in the field 'shadowing' NISP staff (Emerson 2001) - observing how they conducted workshops, events, meetings with firms, engaged firms directly on particular exchanges, and presented themselves at industry events. We supplemented these observation data with archival documents from NISP. These internal and publicly available 
documents included company and regional analyses and reports, public case studies, and access to NISP's proprietary resource and project management database known as CRISP. The CRISP database proved very useful for quantitatively analyzing West Midlands IS growth as it included cumulative archiving of all IS exchanges and their development status (from initial agreement to pursue an exchange to formalization and ongoing resource exchange). Our IS exchange data (summarized in table 1) begins in early 2005, when the West Midlands program (started in 2002) began formally cataloguing its IS exchange data. For this study, 'IS exchange' refers to by-product and other excess resource sharing and/or exchanging between firms. Additionally, we distinguish between 'active' exchanges (where resources were or are actively exchanged and / or shared) and exchanges 'under development' (where partnering firms are developing and negotiating the exchange particulars).

\section{TABLE 1 HERE}

Table 1 shows an increase in firms in the IS network - from 162 in 2005 to 333 in 2009; and IS exchanges - from 174 to 436 during the same period. Our data, and other work on NISP (Mirata 2004), suggests little IS knowledge or activity in the West Midlands prior to this program. In other words, West Midlands IS activity developed from zero to over $\mathbf{4 0 0}$ exchanges in eight years. Our data also show that, while a small number of firms dropped out of the network during our study (mainly due to facility closures); most firms stayed and many engaged in multiple exchanges over time. 
By separating active from under-development exchanges, we also traced the exchange maturation by comparing active exchanges to those under development. Finally, we computed average number of exchanges per firm; the upward trend suggesting firms were re-engaging in IS exchanges and new firms were joining the network. While we discuss these trends in our findings, we note this latter point supports previous work suggesting firms are more likely to develop new exchanges than stop participating in existing ones (Ehrenfeld and Chertow 2002).

$<$ Heading 2> Analysis

Our analysis elucidates how NISP engaged firms and probes the impacts of NISP's actions on IS network evolution. We uploaded our data (roughly 2000 pages of interview transcripts and notes, post-interview and observation memos, emails, and archival documents) into ATLAS.ti (a computer assisted qualitative data analysis software, Muhr 2004) to support our analysis efforts. As is typical for a grounded theory approach, we emergently coded these data, focusing on what NISP did (coded as 'actions') and to what effect (coded as 'perceptions') according to NISP staff and engaged firms.

Multiple themes emerged around NISP's facilitation actions and how firms perceived and reacted to NISP's actions over time. We elaborated on and refined these themes to capture specific actions, eventually abstracting and grouping NISP's actions into three categories - conversation, connection, and co-creation - based on patterns developing from our data. For example, a NISP staff member's statement that "it has been most successful going through the chamber of commerce and [another group] ... [to access] production managers" was coded as 'using existing contacts to make new ones' and eventually grouped with other themes within the 'conversation' action category. While these actions existed 
throughout our study period, we also found a changing emphasis on particular actions over time, and changes in how these actions influenced serendipitous and goal-directed network building processes. We paid particular attention to differences between on 2006 and 2009 NISP staff interviews to understand these changes. We worked back and forth between our longitudinal interview data and prior analysis of the network's growth and evolution (reported elsewhere, Paquin and Howard-Grenville 2009) to develop a more holistic temporal understanding of IS network evolution. These findings are discussed below.

<Heading 1> ACTIONS USED TO FACILITATE INDUSTRIAL SYMBIOSIS AND IMPACTS ON UNDERLYING NETWORK PROCESSES

We found NISP engaged in three main types of action as the IS network evolved conversation, connection, and co-creation. As discussed below and summarized in table 2 , each set of actions differentially influenced IS exchange development and the underlying processes of network development. In sum, conversation actions appeared very early on, in a phase we label 'pre-network development,' and created the conditions for serendipitous network processes whereby firms learned of potential IS exchanges and/or partners. Connection actions dominated next, in a phase we label 'earlier network development,' and enabled a goal-directed matching process that directly connected promising IS exchange partners. Finally, in a phase we label 'later network development,' co-creation actions grew in importance and enabled an increase in goal-directed network evolution, specifically through the increasingly 'hands on' selection of particular IS opportunities and participants. The shifting prevalence of these three action types, however, reduced opportunities from serendipitous network processes over time. We discuss each action type below and explain 
how it shaped network evolution through enabling or precluding serendipitous or goaldirected processes.

TABLE 2 HERE

$<$ Heading 2> Conversation Actions

We define conversation as actions that build awareness of and interest in IS among potential participants, and seek to communicate the value that the coordinating organization offers IS development. As a new organization proposing an unfamiliar business practice, NISP needed to recruit potential firms while developing its own credibility as a coordinating organization. These challenges differ from those faced by a coordinating organization that can point to already-successful IS exchanges that might have emerged on their own. Conversation actions typically preceded bringing together specific firms to develop exchanges. Instead, these actions addressed broader institutional aspects of making IS known to firms, easing the way for exchanges to subsequently develop. To paraphrase one NISP executive, these actions involved casting a 'wide net' to generate interest in IS. Note that already this process looks different from a fully goal-directed one where a coordinator might reach out and start making connections between firms.

We highlight specific 'conversation' actions NISP took to find and recruit interested participants. These include: i) taking a strategic view of the region's resource needs to identify potential firms and exchanges, ii) using pre-existing individual and organizational contacts to engage firms, and iii) facilitating 'interaction spaces' where interested individuals could meet and share information. 
Taking a strategic view of a region, NISP staff assembled dossiers, including information on major industrial resource flows, impending regulation, and other knowledge to help them identify and develop IS exchanges. For example, one NISP staffer spoke of a regional 'profile' which "identified ... industries, so we have ' $X$ ' number of construction companies and [know] who they are." By understanding impending regulatory changes, staff began to see which firms may be more interested in learning about IS as a way to adapt. NISP also leveraged existing contacts from established organizations to facilitate introductions. Much of this early work involved cold calling, mailings and emails to firms' production and environmental managers, but, as one NISP manager stated, having introductions from established organizations allowed NISP to leverage others" "networks to basically send out our message."

These actions supported NISP in bringing together firms for its 'Quick Wins' workshops, whereby NISP created interaction spaces through facilitated information exchange and networking activities around sharing individual firms' waste and resource needs. Organized and run with the explicit goal of identifying potential future exchanges, these exchanges came about through serendipitous encounters occurring between firms and NISP staff, based largely on who attended. Described to us colloquially as 'industry speed dating,' these workshops often generated a large number of potential exchanges. As an example of serendipity from these workshops, one firm interviewee recalled, "132 [potential exchanges] came out of the workshop... when [at first] we didn't think there would be any."

$<$ Heading 3> Impact of Conversation Actions on Network Processes: Enabling Serendipity 
Through conversation, NISP cast a wide, but somewhat directed, 'net' to capture the interest of as many firms as possible around IS, a seemingly necessary approach given the lack of prior IS activity in the region. While NISP's intent was clearly goal-driven, its conversation actions generated broad interest and enabled a surprisingly serendipitous process of network development. Some participants found Quick Wins workshops as useful for informal interactions as for the more structured NISP-led resource matching activity. One firm interviewee said of these workshops, "the biggest benefit, possibly immeasurable ... is the conversations you have with people that you wouldn't normally be caught with." Another said "you find novel ideas ... which [you] might not necessarily think about or find out about from the trade associations." In conjunction with these serendipitous processes, regional IS activity grew quickly. While our quantitative data begins only in 2005 , our qualitative data suggests little if any IS activity in the region prior to 2002. Thus, from 2002 to 2005 activity grew from zero to 162 firms and 174 exchanges.

NISP staff learned, however, that potential exchanges typically required considerable investment on their part to bring to fruition. Referring to another workshop, one NISP staff member noted, "We have to go through the process of quantifying the relative importance of those 104 [potential exchanges found during the workshop]... Even if we get down to 10, the investment that it will take for the regional team to deal with that number will be great." Another commented that, "The danger I see for NISP... is promises," suggesting that to deliver on its goal of supporting IS exchanges, NISP would have to reign in some of the expectations generated by serendipitous processes. 
$<$ Heading 2> Connection Actions

NISP used connection actions to bring together relevant firms to develop specific exchanges. We found NISP engaged in two main connection actions: i) strategically introducing relevant firms around specific exchanges and ii) deepening their involvement with particular firms. Both enabled NISP to deliver on its goals more strategically. An important distinction is that while conversation invited all to share ideas in hopes of generating serendipitous encounters and exchange opportunities, connection was directed explicitly towards bringing specific exchanges to fruition.

To enable connection, NISP staff used their developing knowledge of firms in a region, gained partly through conversation actions, to prioritize and select potential exchanges and firms. Given that part of NISP's performance was measured in terms of tonnage diverted from landfill, the size of potential exchanges often influenced these choices. One NISP staffer stated, "you can do a lot of very interesting work, but if it's 23 tonnes, it's not going to do a lot to add up to your 100,000 tonnes [target]." At times NISP sought to bring firms together around 'low hanging fruit,' or fairly straightforward exchanges requiring little additional material reprocessing or technical development. One NISP staff member gave an example:

There is a waste company [with] a biogas program, and they are trying to source ... organic materials ... So one [company] had 20,000 tonnes of food pulps that were going to landfill and it was a quick marriage to get them together.

Additionally, NISP worked to deepen and strengthen relationships with key regional firms and become more involved in selected exchanges. These relationships were necessary as developing new IS exchanges - even 'low hanging fruit' - often took more time and effort than originally anticipated. For example, one NISP staffer described a seemingly simple yet 
failed de-ionized water exchange. The exchange "appeared at the outset to be very simple... but the technicalities of it and the commercial issues did not go well." The receiving firm "start[ed] getting into issues of continuity of supply... [the firms] are actually making ... a simple opportunity much more problematic."

By actively developing and strengthening relationships, often through facility site visits and one-on-one meetings with firm staff, NISP staff built a level of trust with these firms and found they could better support developing new IS exchanges. Through this relationship-building process, "we try to understand the business benefit that might be accruing from a particular opportunity" stated one NISP staffer. This included a more nuanced understanding of a firm's operations and concerns, which could improve NISP's confidence in the firm as an IS partner. One staff member noted, "You don't need to know that much from the company when you start off, but eventually a number of details must be understood." She added, “It isn't just about waste, it's about storage capacity, and it's about whether or not they have expert people or training facilities."

From NISP's performance targets standpoint, relationship development was particularly important. One staffer stated, “larger [IS exchanges] don't tend to drop out by one visit, you need to put in a lot of time and effort, follow up meetings and bringing in other members, so it takes longer to nurture." A NISP executive echoed this, observing "as trust develops... more and more potential resources will come up... [exchanges] that start up one way often end up being quite different." These findings support earlier work on the importance of trust and common norms for IS development (Ashton 2008), and extend it by showing that a coordinator can recognize the need for, and actively facilitate the development of, trust within exchange relationships. Further, we find trust cultivation can 
be pursued simultaneously while developing an IS exchange, rather than only as an outcome.

< Heading 3> Impact of Connection Actions on Network Processes: Increasing Goal-

\section{Directedness}

Connection actions, more than conversation actions, highlight how critical goal-

directed processes are to facilitated IS network formation. Driven by its need to focus resources and prioritize which exchanges to pursue, NISP increased its connection actions, becoming increasingly selective in choosing which exchanges and firms to support. As opposed to casting a wide net to encourage serendipitous encounters, NISP's attention to connection actions supported a network-level goal of aggregate environmental benefit. This evolution appears in 2006 interview data as NISP staff reflected on then recent changes. One staff member noted that "[we] were having a hard time handling all of the phone calls" from interested firms, and another observed "we stopped doing so much publicity."

Moreover, increasing goal-directedness is evident in the network's growth and structure. A rapid increase in network size (firms and exchanges) occurred by 2007 (see table 1), but importantly this was accompanied by an increase in exchanges per firm. This shows firms 're-engaged' the IS network through additional exchanges. Additionally, a larger proportion of exchanges were being completed, suggesting NISP's increasing ability to bring exchanges to fruition, though it may simply capture the time needed to successfully implement an exchange. Separately, we found the most connected firms within the network changed significantly over time (Paquin \& Howard-Grenville, 2009), supporting our observation that connection actions brought together particular firms for particular exchanges, indicating goal-directedness. If serendipitous network processes dominated, we would expect firms in 
the network early on to remain most connected throughout the network's growth (Powell et al. 2005).

$<$ Heading $2>$ Co-Creation Actions

Co-creation actions enabled further shifts in the evolution of the facilitated IS network. We define co-creation as those supporting the development of IS 'infrastructures' around important resource streams. In particular, we found NISP engaged in two sets of actions i) replicating high-value IS exchanges and ii) developing capacity around processing key regional resource streams. These actions happened throughout our study, yet we found NISP engaged more in connection actions later on, as it developed and leveraged its expertise. This happened primarily in two ways.

First, NISP staff sought out replicable high-value IS exchanges (e.g., significant landfill diverted, significant carbon emission reductions). Our 2009 interviews showed a considerable shift in emphasis to such exchanges, relative to our 2006 interviews. For example, one NISP staffer said (in 2009) that he and his team "actively seek [those] companies who may be able to provide feedstock for an anaerobic digester... trying to grow involvement and engagement within the region." Another stated her interest in "returning customers" within construction; that is, "construction companies who come back to us time and time again because they are working on something new." Having developed relationships and expertise about certain types of exchanges from conversation and connection actions, NISP staff could increasingly replicate these, with the same or new firms.

To quantitatively explore this shift towards high-value replicable exchanges, we analyzed construction-material based exchanges in the West Midlands because NISP staff 
mentioned construction several times when discussing such exchanges. Table 3 shows active construction-based exchanges increased more slowly than overall active exchanges (table 1). Yet, construction exchanges accounted for an outsized share of total landfill diverted (a key performance target for NISP) with an almost three-fold increase in landfill diverted per construction exchange. This supports NISP staff's articulated attention to increasingly seeking out replicable and high-value exchanges. Such a trend reflects NISP'S expertise and knowledge accumulation and its pragmatic approach to delivering on an overall network goal by tailoring its engagements with particular firms.

\section{TABLE 3 HERE}

NISP staff also selectively supported what we call 'resource infrastructure' projects. NISP's efforts here were more time-intensive, varied and consultative in nature. These projects include helping develop funding and investment proposals for new and existing firms, providing guidance on environmental permitting, and offering technical or production assistance. These projects often did not directly support new IS exchanges, but laid the foundation for developing future exchanges, through establishing new processing techniques or expanding regional capacity around key resource streams. For example, one NISP staff member spoke of being aware of 'certain gaps in solution providers [firms that could reprocess certain waste streams]' in his region, citing the lack of 'quality composting facilities.'

$<$ Heading 3> Impact of Co-Creation Actions on Network Processes: Reigning in

\section{Serendipity}


With NISP's emphasis on co-creation actions later in the study period, we see a shift in the nature of projects undertaken and a further evolution of network processes. While developing easily replicable IS exchanges seems like a logical next step for a successful coordinating organization, developing resource infrastructures goes beyond coordinating IS (Chertow 2007; Mirata 2004) and towards a broader level of regional resource capacity. Cocreation actions, more than conversation and connection, require relationships and trust with firms and are more goal-directed in nature. As one NISP staffer stated, echoed by many others, "our [firms] are getting more involved in what we are about and we are better at picking [IS exchanges and related projects] we want to get involved with." He continued, "businesses now trust us ... [we] evolve and get bigger projects and more engagement." As Paquin and Howard-Grenville (2009) showed previously, and noted above, co-creation differentially impacts the IS network structure by altering which firms are most connected and central. Combined with the qualitative shifts in actions and changes in the types and number of exchanges, this suggests that goal-directed processes became more dominant later in the network's evolution.

Given NISP's steadily increasingly performance targets, it seems natural that NISP's actions would evoke more goal-directed processes to meet its performance targets. Additionally, NISP's changing funding levels likely also influenced its focus towards specific, replicable exchanges. While NISP’s funding grew from $£ 3.5$ mil to $£ 8.25$ mil between 2005 and 2007, it fell in 2008 to $£ 5.825$ mil (due to UK 'austerity' budgets) and roughly remained there for 2009, though its performance targets were increased. This coincided with the slowing growth of new IS exchanges in the West Midlands from 2008 to 2009 (table 1). One staffer stated in 2009, regarding NISP's funding situation “we couldn't grow the [regional IS] network to the same degree as we have done in the past... What we have been doing is 
taking [exchanges] that have been more likely and helping them through. What with having targets to meet, it's natural." Another stated, the "pipeline is starting to dry up because we are not replenishing it." With these changes, NISP reigned in serendipitous processes that could produce future exchanges. Our 2009 interviews suggest this more heavily goaldirected approach to managing the IS network could jeopardize its long term resilience by squeezing out actions supporting the discovery of future IS exchanges.

\section{$<$ Heading 1> DISCUSSION}

We sought to understand how a facilitator's actions shaped underlying network processes and contributed to IS evolution by exploring how a facilitated IS network evolved over an eight-year period. By considering how NISP's actions evolved over time, our findings add to the emerging conversation on IS evolution (Chertow and Ehrenfeld 2010; Baas and Boons 2004; Doménech and Davies 2010). Our findings suggest 'serendipity' plays an important role in creating IS opportunities for firms even within a facilitated approach. Network orchestration theory (Doz et al. 2000; Dyer and Nobeoka 2000; Dhanaraj and Parkhe 2006) and prior empirical work on facilitated IS (Baas 1998; Kincaid and Overcash 2001 ) indicate goal-directed processes are far more prevalent than serendipitous ones in such settings. Yet, NISP's actions enabled serendipitous processes from the earliest stages of the network, casting a wide net to capture firms' interest and creating interaction spaces where firm members could meet and share ideas. This suggests the value of developing conditions for serendipity even with facilitated or planned IS, at least initially.

Serendipitous processes likely laid the groundwork for the development of cultural embeddedness, as firm managers interacted and established relationships, developing interaction norms and ultimately trust. Serendipity's role in NISP's case was not the same as 
in a fully self-organizing system. In a facilitated network, the coordinator pays careful attention to which firms, industries, and other organizations might be most receptive to developing exchanges. However, we found at least some opportunity for serendipity may be needed to 'kick start' IS of all kinds (i.e., self-organizing, facilitated, or planned), and perhaps is even a minimum condition for the successful establishment of IS. Future work could extend this through the study of different evolving IS networks.

Second, our findings affirm the importance of developing embeddedness, either structurally through connecting firms and individuals in particular exchanges, or culturally through developing trust and shared norms in support of IS. Again, embeddedness has been more generally observed (Boons and Howard-Grenville 2009), but is typically seen as a hallmark of self-organizing, bottom-up systems, dominated by serendipitous network processes. In our case, the coordinating body sought explicitly to deepen its relationships with firms, seeing this as an essential move in shifting from casting a wide net to more selectively developing high value exchanges. Consistent with organizational theory (Dacin et al. 1999; Uzzi 1997), this suggests embeddedness may be a more generalizable feature of robust IS development. It is important to point out different dimensions of embeddedness and how they develop in particular cases, as they will likely differ between various types of IS networks. Our data showed that deepening relationships largely occurred between the coordinator and firms, not necessarily between firms. This is consistent with goal-directed network processes which yield 'hub and spoke' structures (Kilduff and Tsai 2003; Dhanaraj and Parkhe 2006). This arrangement suggests a more structural form of embeddedness than one where participants broadly share commons norms.

Future work could explore specific questions about the role of various dimensions of embeddedness (Boons and Howard-Grenville 2009) in IS evolution. Can one form of 
embeddedness (e.g., structural) substitute for another (e.g., cultural or cognitive)? Do facilitated versus self-organizing systems display different patterns of embeddedness over time? Which dimensions of embeddedness enable or constrain adaptation and which facilitate or inhibit resilience among IS settings (e.g., regional networks, eco-industrial parks)?

Finally, facilitated IS evolution displays some distinct characteristics from prior models of IS development. One difference centers on the interaction of goal-directed and serendipitous processes as IS develops. In our case, goal-directed processes increasingly replaced serendipitous processes as the facilitator increasingly leveraged its specialized knowledge (e.g., firms, resources, exchanges) to deliver on its performance targets. This evolution was necessary for the facilitator to focus its efforts and resources to attain targets set by its funding body. Without such a shift, it is likely that fewer exchanges would have come to fruition and/or that they would have done so over a longer period of time. Conversely, the trajectory of the IS network towards increasingly goal-directed processes raises questions for the renewal of firms, exchanges, and interest in IS overall. As table 1 shows, network growth slowed by the end of the study. By, 2009 NISP staff expressed clear concern that, with fewer opportunities for open interaction and serendipity, the 'pipeline' of future potential exchanges was drying up. In some ways, this tension represents a classic organizational dilemma for the need to both 'exploit' one's core competencies in delivering on today's goals, while 'exploring' new opportunities for tomorrow's goals (Tushman and Anderson 1986).

Facilitation in any system, even one that emerged and only gained a coordinating body later on, faces this dilemma. To what degree can the coordinating body's actions effectively leverage accumulated relationships, knowledge, and experience, yet 
simultaneously allow for serendipitous renewal through unplanned interactions? This dilemma arises whether a coordinator is an individual (c.f., IS champion, Hewes and Lyons 2008) or an organization (c.f., local authority, von Malmborg 2004; or anchor tenant, Korhonen 2001), but may be particularly acute when the coordinator manages a large number of relationships. Ultimately, network resiliency rests on a network's ability to adapt to changes while remaining useful for participants. Some have argued that all networks are only dynamically stable, that is ties dissolve and form over time while the network as a whole continues (Kilduff et al. 2006). Again, IS research suggests a similar dynamic stability, where individual exchanges may start and stop, but the network endures (Ehrenfeld and Chertow 2002; Doménech and Davies 2010). Future work could explore how facilitators and participants manage the emergent challenges of maintaining and renewing IS network ties. Our research suggests that maintenance and renewal demand an appropriate balance of goal-directed and serendipitous processes, respectively.

$<$ Heading $1>$ CONCLUSION

Our exploration of facilitated IS evolution contributes to previous efforts to theorize IS development (Baas and Boons 2004; Chertow and Ehrenfeld 2010; Doménech and Davies 2010). We raise a number of questions that suggest we are just beginning to understand how different conditions and approaches influence IS evolution. Two directions seem especially fruitful to pursue - how different dimensions of embeddedness arise and interact in different IS arrangement types and how to better understand the interaction of serendipitous and goal-directed processes within and across different IS settings. Just as neither process is expected to exist in 'pure' form in network development (Kilduff and Tsai 2003), neither is one or the other expected to fully dominate IS network evolution. 
Understanding the role these different processes play and their relative prevalence over time will help us understand the dynamic processes underpinning IS networks. 
Table 1: Industrial Symbiosis Growth in the West Midlands

\begin{tabular}{|c|c|c|c|c|c|}
\hline & 2005 & $\begin{array}{c}2006 \\
\text { (1-yr change) }\end{array}$ & $\begin{array}{c}2007 \\
\text { (1-yr change) }\end{array}$ & $\begin{array}{c}2008 \\
\text { (1-yr change) }\end{array}$ & $\begin{array}{c}2009 \\
\text { (1-yr change) }\end{array}$ \\
\hline $\begin{array}{l}\text { All Firms } \\
\text { - Firms with active IS exchanges }\end{array}$ & $\begin{array}{r}162 \\
72\end{array}$ & $\begin{array}{r}180(11 \%) \\
92(28 \%)\end{array}$ & $\begin{array}{l}243(35 \%) \\
116(26 \%)\end{array}$ & $\begin{array}{l}309(27 \%) \\
155(34 \%)\end{array}$ & $\begin{array}{l}333(8 \%) \\
167(8 \%)\end{array}$ \\
\hline $\begin{array}{l}\text { All IS exchanges } \\
\text { - Active IS exchanges } \\
\text { - Under development IS exchanges }\end{array}$ & $\begin{array}{r}174 \\
60 \\
114\end{array}$ & $\begin{array}{r}207(19 \%) \\
83(38 \%) \\
124(9 \%)\end{array}$ & $\begin{array}{l}308(49 \%) \\
113(36 \%) \\
195(57 \%)\end{array}$ & $\begin{array}{l}401(30 \%) \\
176(56 \%) \\
225(15 \%)\end{array}$ & $\begin{array}{r}436(9 \%) \\
189(7 \%) \\
247(10 \%)\end{array}$ \\
\hline $\begin{array}{l}\text { Exchanges per Firm } \\
\text { - Active exchanges per Firm involved in an } \\
\text { active exchange }\end{array}$ & $\begin{array}{l}2.15 \\
1.67\end{array}$ & $\begin{array}{l}2.30 \\
1.80\end{array}$ & $\begin{array}{l}2.53 \\
1.95\end{array}$ & $\begin{array}{l}\mathbf{2 . 6 0} \\
2.27\end{array}$ & $\begin{array}{l}2.62 \\
2.26\end{array}$ \\
\hline
\end{tabular}

Note: Formal data collection on particular IS exchanges did not occur until 2005. By then, the program included all exchanges up to 2005 in its 2005 count, and counted exchanges and firms cumulatively going forward. 
Table 2: NISP's Actions, Impacts, and Nature of IS Network Evolution

\begin{tabular}{|c|c|c|c|}
\hline & & & \\
\hline & Conversation & Connection & Co-Creation \\
\hline Impacts* & $\begin{array}{l}\text { 'Pre' Network Development } \\
\text { (c.2002-2005) } \\
\text { - Captures firms' interest, lead to broader } \\
\text { institutional awareness } \\
\text { - Potential exchanges found through } \\
\text { workshops and events }\end{array}$ & $\begin{array}{l}\text { 'Earlier' Network Development } \\
\text { (Throughout the study period) } \\
\text { - Selective exchanges supported from (i) } \\
\text { conversation actions and (ii) strategic choices } \\
\text { - Deeper relationships, trust developed } \\
\text { - Firms 're-engage' in new exchanges }\end{array}$ & $\begin{array}{l}\text { 'Later' Network Development } \\
\text { (c.2007 onward) } \\
\text { - Selected firms increasingly engaged around } \\
\text { replicable exchanges } \\
\text { - Selected complex projects to support future IS } \\
\text { exchanges }\end{array}$ \\
\hline $\begin{array}{l}\text { Network } \\
\text { Evolves } \\
\text { Through: }\end{array}$ & $\begin{array}{l}\text { Primarily Serendipitous Processes } \\
\text { - Reliant on broad interest generation and } \\
\text { serendipitous encounters and idea sharing }\end{array}$ & $\begin{array}{l}\text { Mix of Serendipitous and Goal-Directed Processes } \\
\text { - Strategic selection of firms \& exchanges based on } \\
\text { performance targets yet also influenced by } \\
\text { serendipity of conversation actions }\end{array}$ & $\begin{array}{l}\text { Increasingly Goal-Directed Processes } \\
\text { - Strategic selection of firms \& exchanges based on } \\
\text { performance targets } \\
\text { - Strategic selection of 'resource infrastructure' } \\
\text { projects based on pragmatic experience }\end{array}$ \\
\hline
\end{tabular}

* Dates do not denote different 'stages' of the IS network per se, rather they illustrate when a given set of actions were more prominent in the data 
Table 3: Growth and Impact of Construction-based Industrial Symbiosis Exchanges

\begin{tabular}{|l|r|r|r|r|r|}
\hline & 2005 & 2006 & \multicolumn{1}{|c|}{2007} & \multicolumn{1}{|c|}{2008} & 2009 \\
\hline $\begin{array}{l}\text { Construction Exchanges } \\
\text { - \% of all active exchanges }\end{array}$ & 17 & 22 & 34 & 37 & 40 \\
\hline $\begin{array}{l}\text { Total Landfill diverted from Construction } \\
\text { exchanges ('000 tonnes) }\end{array}$ & $27 \%$ & $30 \%$ & $21 \%$ & $21 \%$ \\
$\begin{array}{l}\text { - \% of construction landfill diverted from all landfill } \\
\text { diverted }\end{array}$ & 148.6 & 279.4 & 548.3 & 781.7 & 831.7 \\
\hline $\begin{array}{l}\text { Landfill diverted per construction } \\
\text { Exchange ('000 tonnes) }\end{array}$ & $30 \%$ & $40 \%$ & $78 \%$ & $72 \%$ & $73 \%$ \\
\hline
\end{tabular}

Note: These include only exchanges which are active, meaning resources have or are currently being exchanged 


\section{ACKNOWLEDGEMENTS}

We benefited from feedback on earlier versions of this paper from Peter Laybourn, Rachel Lombardi and participants at the 2011 ISIE conference session. The authors thank the National Industrial Symbiosis Programme for providing access and support for this research; Don Lyons and our anonymous reviewers for their insight in developing these ideas.

\section{REFERENCES}

Ashton, W. 2008. Understanding the organization of industrial ecosystems: A social network approach. Journal of Industrial Ecology 12(1): 34-51.

Baas, L. 1998. Cleaner production and industrial ecosystems, a Dutch experience. Journal of Cleaner Production 6(3-4): 189-197.

Baas, L. W. and F. A. Boons. 2004. An industrial ecology project in practice: exploring the boundaries of decision-making levels in regional industrial systems. Journal of Cleaner Production 12(8-10): 1073-1085.

Baum, J. A. C., A. V. Shipilov, and T. J. Rowley. 2003. Where do small worlds come from? Industrial \& Corporate Change 12(4): 697-725.

Boons, F. A. and J. Howard-Grenville, eds. 2009. The Social Embeddedness of Industrial Ecology. Cheltenham, UK: Edward Elgar.

Burt, R. S. 1992. Structural Holes: The Social Structure of Competition. Cambridge, MA: Harvard University Press.

Capaldo, A. 2007. Network structure and innovation: The leveraging of a dual network as a distinctive relational capability. Strategic Management Journal 28: 585.

Chertow, M. and J. Ehrenfeld. 2010. Organizing self-organizing systems: Toward a theory of industrial symbiosis. Journal of Industrial Ecology Submitted for publication.

Chertow, M., W. Ashton, and J. Espinosa. 2008. Industrial symbiosis in Puerto Rico: Environmentally related agglomeration economies. Regional Studies 42: 1299-1312.

Chertow, M. R. 2007. "Uncovering" Industrial Symbiosis. Journal of Industrial Ecology 11(1): 11-30.

Dacin, M. T., M. J. Ventresca, and B. D. Beal. 1999. The Embeddedness of Organizations: Dialogue \& Directions. Journal of Management 25(3): 317-356.

Dhanaraj, C. and A. Parkhe. 2006. Orchestrating innovation networks. Academy of Management Review 31(3): 659-669.

Dietz, T., E. Ostrom, and P. C. Stern. 2003. The struggle to govern the commons. Science 302(5652): 1907-1912.

Doménech, T. and M. Davies. 2010. The role of embeddedness in industrial symbiosis networks: Phases in the evolution of industrial symbiosis networks. Business Strategy and the Environment.

Doz, Y. L., P. M. Olk, and P. S. Ring. 2000. Formation processes of R\&D consortia: which path to take? Where does it lead? Strategic Management Journal 21(3): 239-266.

Dyer, J. H. and K. Nobeoka. 2000. Creating and managing a high performance knowledgesharing network: The Toyota case. Strategic Management Journal 21: 345-367. 
Ehrenfeld, J. and N. Gertler. 1997. Industrial Ecology in Practice: The Evolution of Interdependence at Kalundborg. Journal of Industrial Ecology 1(1): 67-79.

Ehrenfeld, J. R. and M. R. Chertow. 2002. Industrial symbiosis: The legacy of Kalundborg. In Handbook of Industrial Ecology, edited by R. U. Ayres and L. W. Ayres. Cheltenham, UK: Edward Elgar.

Emerson, R. M. 2001. Contemporary Field Research: Perspectives and Formulations. 2nd ed. Prospect Heights, IL: Waveland Press.

Gibbs, D. and P. Deutz. 2007. Reflections on implementing industrial ecology through ecoindustrial park development. Journal of Cleaner Production 15(17): 1683-1695.

Glaser, B. G. and A. Strauss. 1967. The Discovery of Grounded Theory: Strategies for qualitative research. Chicago, IL: Aldine Publishing Co.

Granovetter, M. S. 1985. Economic action and social structure: The problem of embeddedness. American Journal of Sociology 91(3): 481-510.

Gulati, R. and M. Gargiulo. 1999. Where do interorganizational networks come from? The American Journal of Sociology 104(5): 1439-1493.

Hewes, A. K. and D. I. Lyons. 2008. The Humanistic Side of Eco-Industrial Parks: Champions and the Role of Trust. Regional Studies 42: 1329-1342.

Howard-Grenville, J. and R. L. Paquin. 2008. Organizational dynamics in industrial ecosystems: Insights from organizational theory. In Dynamics of Industrial Ecosystems, edited by M. Ruth and B. Davidsdottir: Edward Elgar.

Human, S. E. and K. G. Provan. 2000. Legitimacy building in the evolution of small-firm multilateral networks: A comparative study of success and demise. Administrative Science Quarterly 45(2): 327-365.

Kilduff, M. and W. Tsai. 2003. Social Networks and Organizations. Thousand Oaks, CA: Sage.

Kilduff, M., W. Tsai, and R. Hanke. 2006. A paradigm too far? A dynamic stability reconsideration of the social network research program. Academy of Management Review 31(4): 1031-1048.

Kincaid, J. and M. Overcash. 2001. Industrial Ecosystem Development at the Metropolitan Level. Journal of Industrial Ecology 5(1): 117-126.

Korhonen, J. 2001. Co-production of heat and power: an anchor tenant of a regional industrial ecosystem. Journal of Cleaner Production 9(6): 509-517.

Langley, A. 1999. Strategies for theorizing from process data. Academy of Management Review 24(4): 691-710.

Mirata, M. 2004. Experiences from early stages of a National Industrial Symbiosis Programme in the UK: Determinants and coordination challenges. Journal of Cleaner Production 12: 967-983.

Muhr, T. 2004. ATLAS.ti Berlin: ATLAS.ti Scientific Software Development GmbH.

Paquin, R. L. and J. Howard-Grenville. 2009. Facilitating regional industrial symbiosis: Network growth in the UK's National Industrial Symbiosis Programme. In The Social

Embeddedness of Industrial Ecology, edited by F. A. Boons and J. Howard-Grenville. London, UK: Edward Elgar.

Patton, M. Q. 2001. Qualitative Research \& Evaluation Methods. 3 ed: Sage.

Powell, W. W., K. W. Koput, and L. Smith-Doerr. 1996. Interorganizational collaboration and the locus of innovation: Networks of learning in biotechnology. Administrative Science Quarterly 41(1): 116-145. 
Powell, W. W., K. Packalen, and K. Whittington. 2009. Organizational and institutional genesis: The emergence of high-tech clusters in the life sciences. In The Emergence of Organization and Markets, edited by J. Padgett and W. W. Powell.

Powell, W. W., D. R. White, K. W. Koput, and J. Owen-Smith. 2005. Network dynamics and field evolution: The growth of inter-organizational collaboration in the life sciences. American Journal of Sociology 110(4): 1132-1205.

Salancik, G. R. 1995. WANTED: A good network theory of organization. Administrative Science Quarterly 40: 345-349.

Shi, H., M. Chertow, and Y. Song. 2010. Developing country experience with eco-industrial parks: a case study of the Tianjin Economic-Technological Development Area in China. Journal of Cleaner Production 18(3): 191-199.

Tushman, M. L. and P. Anderson. 1986. Technological discontinuities and organizational environments. Administrative Science Quarterly 31(3): 439.

Uzzi, B. 1996. The sources and consequences of embeddedness for the economic performance of organizations: The network effect. American Sociological Review 61(4): 674.

Uzzi, B. 1997. Social Structure and Competition in Interfirm Networks: The Paradox of Embeddedness. Administrative Science Quarterly 42(1): 37-69.

Van Beers, D., G. Corder, A. Bossilkov, and R. Van Berkel. 2007. Industrial Symbiosis in the Australian Minerals Industry. Journal of Industrial Ecology 11(1): 55-72.

von Malmborg, F. 2004. Networking for knowledge transfer: Towards an understanding of local authority roles in regional industrial ecosystem management. Business Strategy and the Environment 13(5): 334.

\section{ABOUT THE AUTHORS}

Raymond Paquin is an Assistant Professor at the John Molson School of Business, Concordia University in Montreal, Quebec, Canada.

Jennifer Howard-Grenville is an Associate Professor at the Lundquist College of Business, University of Oregon in Eugene, Oregon, USA. 